\title{
BILATERAL PULMONARY AGENESIS
}

\author{
BY \\ ALBERT E. CLAIREAUX and H. P. FERREIRA \\ From the Institute of Obstetrics and Gynaecology, University of London
}

(RECEIVED FOR PUBLICATION DECEMBER 6, 1957)

Absence of one lung is an unusual malformation and has been the subject of an extensive review by Smart (1946) who was able to trace 33 cases of complete absence of one lung. A much more rare anomaly is complete absence of both lungs. Only three cases appear to be recorded in the literature. The first was reported by Schmit (1893) from Germany and the others by Allen and Affelbach (1925) and by Tuynman and Gardner (1952) from America. The following report appears to be the first of its kind from this country.

\section{Case Report}

The mother was a healthy primigravida aged 18 years. Apart from the usual childhood illnesses, including measles, she had been well up to the time of her pregnancy. She had no illness during pregnancy. The estimated date of delivery was May 2, 1957. When first seen on November 24, 1956, she was 18 weeks pregnant. She was Group A, Rhesus positive and the Wassermann reaction was negative. The pregnancy continued normally and labour began spontaneously at term on May 3, 1957. She was then admitted to hospital following an antepartum haemorrhage of about $100 \mathrm{ml}$. of blood. She was delivered of a male infant on May 4, 1957 , following slight further blood loss.

The infant's colour was good at birth, it made several attempts at respiration and was said to have 'breathed'. A few minutes after delivery it was noted to be pale and limp. Resuscitation was attempted but was unsuccessful and heart sounds ceased 15 minutes after delivery.

Necropsy. At necropsy on May 5 the body was that of a rather small male infant weighing $2,500 \mathrm{~g}$. and measuring $48 \mathrm{~cm}$. in length. No congenital abnormality was found on external examination.

The falx and tentorium were intact. The brain was firm and no lesion was found on slicing.

When the thorax was opened the heart was seen to be occupying the right half of the thorax. The left side of the chest was occupied by a large thymus. Petechial haemorrhages were present in the parietal pleura and pericardium. There was no lung tissue visible and no bronchial structure was seen. The trachea was identified and was removed together with the larynx. It was noted that the trachea ended blindly (Fig. 1) and there was no

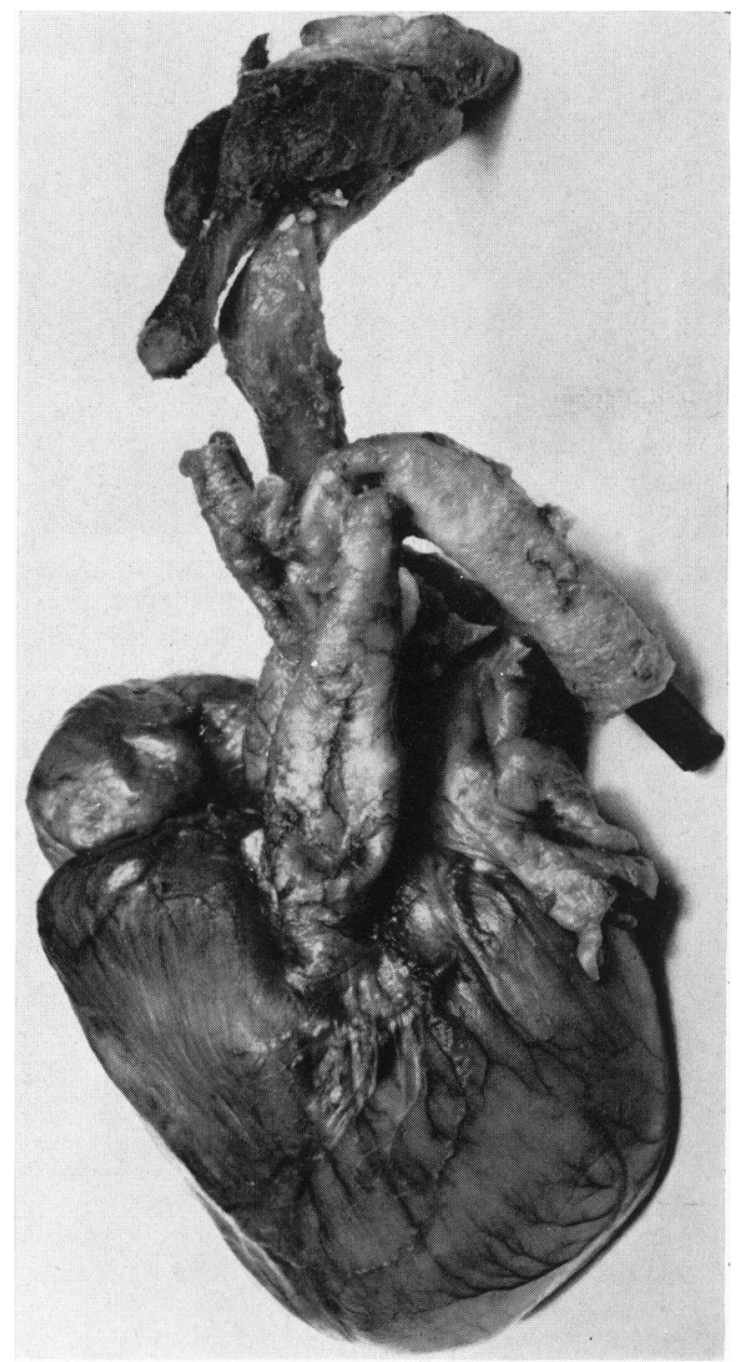

Fig. 1.-Anterior and lateral view of trachea showing rounded lower end and absence of bronchial buds. The intact oesophagus lies posteriorly. The pulmonary trunk, without branching, enters the aorta which is narrow proximally. A marker is inserted into the thoracic aorta. 
evidence of an attempt at the formation of bronchial buds. The trachea measured $1.7 \mathrm{~cm}$. in length and $0.5 \mathrm{~cm}$. in diameter and only two poorly formed cartilagenous rings were found. It was uniform in size throughout its length and had a round end. The larynx was apparently normal. The mucosa lining the larynx and trachea was yellowish in colour.

The heart was of the expected size. There was anomalous venous drainage with a left superior vena cava opening into the left atrium (Fig. 2). The right

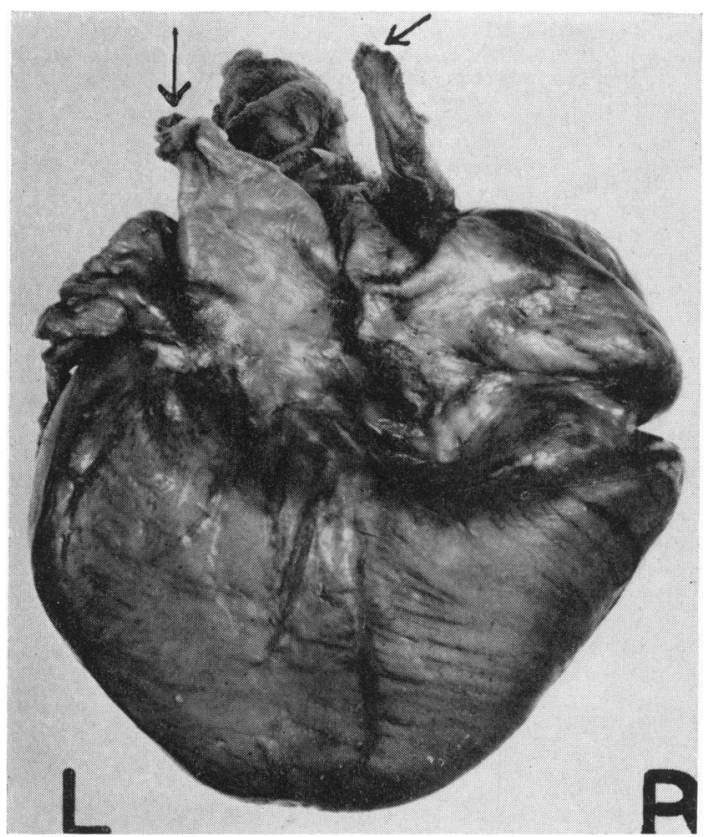

FIG. 2.-Posterior view of heart showing right and left superior vena cava (arrowed). Note absence of pulmonary veins.

superior vena cava and the inferior vena cava opened into the right atrium in the usual way. There was a defect in the inter-atrial septum. The tricuspid valve had a normal appearance. The pulmonary valve was also normal. The pulmonary trunk was of the usual calibre and $2 \cdot 8 \mathrm{~cm}$. above the pulmonary valve it joined the aorta distal to the point of origin of the left subclavian artery. There were no pulmonary arteries. The interventricular septum was intact. The aortic and mitral valves had a normal appearance. The left atrium was rather small and there were no pulmonary veins. The chamber received the left superior vena cava.

The aorta arose in the usual manner and the coronary arteries had a normal appearance. The aortic arch was directed to the left and the descending thoracic aorta showed no abnormality. There were no bronchial arteries. The arch of the aorta was abnormal. Coarctation was present for a distance of $1 \mathrm{~cm}$. between the origin of the innominate artery and the point where the pulmonary trunk entered. In the narrow segment of the arch the aorta was just under half the diameter of the proximal portion. The oesophagus was intact and of the usual calibre.

The peritoneum was healthy and no lesions were present in the stomach or bowel. There was no transposition of the abdominal organs. The liver was of the expected size and no lesion was found on slicing. The diaphragm reached the level of the fourth interspace on each side. The spleen and lymph nodes were normal. There was no abnormality in the genito-urinary tract.

An anatomical diagnosis of bilateral pulmonary agenesis was made. There was congenital malformation of the heart with anomalous left superior vena cava and inter-atrial septal defect; absence of the right and left pulmonary arteries (the pulmonary trunk continuing straight into the aorta); and coarctation of the aorta.

\section{Discussion}

Complete absence of both lungs is of course incompatible with life and is thus of much less clinical importance than absence of one lung. Nevertheless, it is interesting to note that an attempt at respiration was made in all cases so far reported. It thus seems certain that the initiation of respiratory movement does not depend on the presence of lung tissue. Additional malformations in our case were confined to the heart. In the case reported by Schmit (1893) the trachea was connected with the oesophagus and there was a bony abnormality in the neck. The infant described by Tuynman and Gardner (1952) had an accessory spleen. Our case also differs from that of Allen and Affelbach (1925) in that the trachea ended abruptly, but in their case and in the one reported by Tuynman and Gardner, primitive bronchial buds were present.

The cardiac malformations are also slightly different in all three cases. The pulmonary artery joined the aorta at the point where the aorta and ductus arteriosus normally meet in all the cases. The left auricle received no vessels at all in the cases of Schmit and of Allen and Affelbach. In our case an anomalous superior vena cava entered this chamber and in the case reported by Tuynman and Gardner the inferior vena cava drained into it. In their case also, the aortic arch was directed to the right, a change which was absent in the others. A patent foramen ovale was reported by Schmit and by Allen and Affelbach and in our case the interatrial septum was deficient. Our specimen was also unique in showing a coarctation of the aorta.

According to Arey (1940) primary bronchial budding occurs at the $4 \mathrm{~mm}$. stage of the embryo, i.e. at about the fourth week of pregnancy. It would appear, therefore, that the further development of the respiratory tract was interrupted just prior to this. The abnormalities in the heart and 
great vessels are presumably the consequence of the failure of pulmonary development. Ellis (1917), however, has suggested that vascular anomalies may be the primary lesion. This does not appear to be likely in the present case as the development of the heart commences at about the $4 \mathrm{~mm}$. stage.

Severe congenital malformations are known to follow certain virus infections in the mother, notably rubella. There was no history of any such infection in the present case. It is possible that the pulmonary and cardiovascular anomalies were genetically determined but the actual cause of the defect, as with most other congenital abnormalities, remains obscure.

\section{Summary}

A case of bilateral pulmonary agenesis in an infant born at term is reported. In addition to absence of both lungs there were a number of cardiac abnormalities, including an anomalous left superior vena cava and an inter-atrial septal defect.

We are indebted to Mr. E. Clark of the Bernhard Baron Memorial Research Laboratories, Queen Charlotte's Maternity Hospital, London, for the photographs.

\section{REFERENCES}

Allen and Affelbach (1925). Surg. Gynec. Obstet., 41, 375.

Arey, L. B. (1940). Developmental Anatomy. 4th ed. W. B. Saunders and Co., Philadelphia. p. 233.

Ellis, A. G. (1917). Amer. J. med. Sci., 154, 33

Schmit, H. (1893). Virchows Arch. path. Anat., 134, 25.

Smart, J. (1946). Quart. J. Med., 15 n.s. 125.

Tuynman, P. E. and Gardner, L. W. (1952). A.M.A. Arch. Path., 54, 306 . 